\title{
THE LIMITS OF MORPHOMETRIC FEATURES FOR THE IDENTIFICATION OF BLACK-LIP PEARL OYSTER (PINCTADA MARGARITIFERA) LARVAE
}

\author{
ALAIN PAUGAM, ${ }^{1}$ CHRISTINE D'OLLONE, ${ }^{1}$ JEAN-CLAUDE COCHARD, ${ }^{2}$ PIERRE GAREN ${ }^{2 *}$ \\ AND MARCEL LE PENNEC ${ }^{1}$ \\ ${ }^{1}$ Laboratoire des Sciences de l'Environnement Marin (LEMAR), Institut Universitaire Européen de la \\ Mer, Place Nicolas Copernic, 29280 Plouzané, FRANCE; ${ }^{2}$ IFREMER, Centre du Pacifique, BP 7004, \\ 98719 Taravao, Tahiti, French Polynesia
}

\begin{abstract}
As with most cultivated bivalves, culture of the Tahitian pearl oyster Pinctada margaritifera is particularly dependent on the natural environment, especially for spat supply. The ability to track in real time the abundance and the development of pearl oyster larvae in the plankton would help optimize spat collection in atolls of French Polynesia. However no identification criteria are available for the larvae of several bivalves species present in the lagoons and it is not yet possible to specifically monitor pearl oyster larvae. The aim of this study is to determine the most pertinent morphological identification criteria, to specifically identify the larvae of $P$. margaritifera and differentiate them from those of three other abundant species: Pinctada maculata, Crassostrea cuculata and Chama sp. The method of image analysis after photon microscopy was assessed. It allowed automatic measurement of numerous morphometric features that were tested alone or in combination and identification threshold for $P$. margaritifera larvae were determined by statistical analyses. These results led to a key that allowed correct identification for $77 \%$ of $P$. margaritifera larvae. The hinge diagnosis method under scanning electron microscopy, a prime method for the identification of specific criteria on bivalve larva shells, was also used on larvae of both Pinctada species. The two species could be differentiated precisely because of specific differences in the thickness of their hinge provinculum and the number of denticles it bears. However this approach is too time-consuming and technically demanding to use in real time field studies. This study showed the limitations of image analysis as an identification tool of the $P$. margaritifera larvae, but proper statistical analyses and especially the decision tree approach could be used to evaluate and efficiently prioritize the choice of the species identification criteria.
\end{abstract}

KEY WORDS: Pinctada margaritifera, larval identification, morphological features

\section{INTRODUCTION}

The culture of the pearl oyster Pinctada margaritifera (Linné, 1758 ) is a recent activity in French Polynesia. It developed rapidly in the 1980s and today represents the second source of income after tourism. Production reached its peak in 2000 with more than 11 tons of raw pearls with a value of 168 million Euros and generated 7,000 jobs in more than 1,000 farms spread out over some 30 islands. Subsequently, the pearl industry faced a crisis caused by a steep drop in pearl prices, which started in 2001. Export values were 122 million Euros in 2002 and 84 million Euros in 2003 for tonnages of 11 tons and 10 tons respectively. This was mostly because of a very swift and poorly controlled increase in production that entailed a perceptible drop in quality. This crisis highlighted the necessity to organize the market, and also to regulate and to sustain production.

To a large extent, the culture of the Pinctada margaritifera oyster in French Polynesia depends on the natural environment and it relies entirely on the supply of collected spat. The professionals set their collectors up in an empirical way based on their past observations, but spat yields show a large spatio-temporal variability (Cabral et al. 1985, Brié, pers. comm., 1999). The ability to follow-up the larvae during their pelagic life could be useful to predict the periods and places of post larvae settlement and would thus help to improve spat collection as well as spat quality. Tools are therefore needed for the identification of pearl oyster larvae in plankton samples. To our knowledge, no attempt has been made so far to identify any of the bivalve larvae present in the waters of French Polynesian atolls. Techniques allowing larvae of $P$. margaritifera to be recognized among the larvae of other bivalves

*Corresponding author. E-mail: Pierre.Garen@ifremer.fr must be developed. Such approaches should, in particular, allow the distinction between larvae of Pinctada margaritifera and of $P$. maculata (Gould, 1850), which could be a competitor for settlement sites.

The identification of sampled larvae is always difficult and a review of techniques currently available is given in Garland and Zimmer (2002). Techniques of image analysis are explored here as a first step towards the field identification of pearl oyster larvae. The aim of this study is to evaluate the main morphological descriptors of the larvae of 4 common species in the plankton samples from Polynesian pearl farming atolls: $P$. margaritifera, $P$. maculata, Crassostrea cuculata and Chama sp. (Broderip, 1834).

Image analysis was retained as a working method to increase the number of descriptive variables of the study. Automated analysis on computer would also greatly help in reducing the subjectivity of optical methods. Univariate and multivariate statistical treatments were then applied. These methods identified the most pertinent morphological characteristics for identification of these 4 species of bivalves.

\section{MATERIAL AND METHODS}

\section{Larval Samples From the Hatchery}

The larvae of four main bivalve species present in the Polynesian atolls were reared in hatchery up to metamorphosis. Chama sp, Crassostrea cuculata and Pinctada margaritifera larvae were produced at the Service de la Perliculture in Rangiroa. Pinctada maculata and Pinctada margaritifera larvae were produced at Ifremer, Center du Pacifique in Tahiti,

Samples were taken on a regular basis in rearing tanks to obtain larvae of various ages ranging from 1-24 days (Table 1). 
TABLE 1.

Species and age of analyzed larvae.

\begin{tabular}{|c|c|c|c|c|c|}
\hline \multirow{2}{*}{$\begin{array}{c}\text { Stage } \\
\text { (aver.) }\end{array}$} & \multirow{2}{*}{$\begin{array}{l}\text { Age } \\
\text { in } \\
\text { Days }\end{array}$} & \multirow{2}{*}{$\frac{\text { Chama sp. }}{\text { Number }}$} & \multirow{2}{*}{$\frac{\text { C. cuculata }}{\text { Number }}$} & \multirow{2}{*}{$\frac{P . \text { maculata }}{\text { Number }}$} & \multirow{2}{*}{$\frac{P . \text { margaritifera }}{\text { Number }}$} \\
\hline & & & & & \\
\hline \multirow[t]{7}{*}{$\mathrm{D}$} & 1 & 5 & 1 & & 7 \\
\hline & 2 & & 24 & & \\
\hline & 3 & & & & 44 \\
\hline & 4 & 12 & 7 & & \\
\hline & 5 & & & & 98 \\
\hline & 6 & 14 & 10 & 9 & \\
\hline & 7 & & & & 104 \\
\hline \multirow[t]{8}{*}{$\mathrm{U}$} & 8 & & 13 & & \\
\hline & 9 & & & & 85 \\
\hline & 10 & 33 & 5 & 70 & \\
\hline & 11 & & & 72 & 128 \\
\hline & 13 & 18 & 2 & 94 & 160 \\
\hline & 15 & & & & 38 \\
\hline & 16 & & & 78 & \\
\hline & 17 & 36 & 2 & & 49 \\
\hline \multirow[t]{7}{*}{$\mathbf{P}$} & 19 & 28 & & & 222 \\
\hline & 20 & & & 106 & \\
\hline & 21 & & & & 73 \\
\hline & 22 & 27 & 26 & 76 & \\
\hline & 23 & & & & 72 \\
\hline & 24 & & & 11 & \\
\hline & Total & 173 & 90 & 516 & 1080 \\
\hline
\end{tabular}

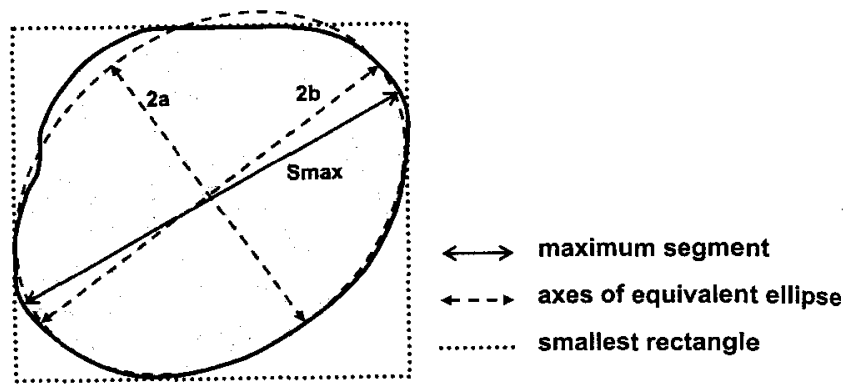

Figure 1. Representation on a larva contour of the dimensions used for calculating 3 (Smax, 2a/2b, Comp) of the 6 parameters retained for the morphometric analysis.

\section{Morphological Observations}

Larvae were observed with a LEITZ DMRE photon microscope. A RGB mode (Red, Green, Blue) digitized picture was acquired for each of the larvae and was analyzed with Optilab software.

Each of the RGB pictures was separated into 3 distinct layers, green, red and blue. Only the green layer was retained, because it presented the highest saturation levels and it was converted into the 256 gray level mode. The areas representing larvae were those having the highest values of gray. The automatic selection of all the pixels was done depending on their value of gray and the smallest value of gray corresponding to the bivalve larvae was empirically determined for each picture. This value was retained as

TABLE 2.

Mean and SE for each variable measured for each stage of each species.

\begin{tabular}{|c|c|c|c|c|c|c|c|}
\hline & \multirow[b]{2}{*}{ Species/Stage } & \multicolumn{2}{|c|}{ D } & \multicolumn{2}{|c|}{$\mathbf{U}$} & \multicolumn{2}{|c|}{$\boldsymbol{P}$} \\
\hline & & Mean & SD & Mean & SD & Mean & SD \\
\hline \multirow[t]{4}{*}{$S \max$} & P. margaritifera & 157.03 & 61.37 & 168.94 & 76.45 & 206.91 & 72.07 \\
\hline & P. maculata & 134.95 & 25.15 & 136.42 & 31.88 & 208.73 & 21.75 \\
\hline & Chama sp. & 173.15 & 42.45 & 413.66 & 19.47 & 159.58 & 65.56 \\
\hline & C. cuculata & 184.37 & 38.40 & 276.37 & 57.78 & 382.26 & 35.86 \\
\hline \multirow[t]{4}{*}{$2 a / 2 b$} & P. margaritifera & 1.298 & 0.151 & 1.255 & 0.131 & 1.286 & 0.145 \\
\hline & P. maculata & 1.389 & 0.155 & 1.312 & 0.159 & 1.347 & 0.148 \\
\hline & Chama sp. & 1.205 & 0.119 & 1.307 & 0.142 & 1.297 & 0.151 \\
\hline & C. cuculata & 1.228 & 0.102 & 1.197 & 0.144 & 1.272 & 0.108 \\
\hline \multirow[t]{4}{*}{ Elong } & P. margaritifera & 1.414 & 0.089 & 1.401 & 0.078 & 1.416 & 0.087 \\
\hline & P. maculata & 1.492 & 0.096 & 1.428 & 0.097 & 1.394 & 0.079 \\
\hline & Chama sp. & 1.354 & 0.055 & 1.379 & 0.053 & 1.412 & 0.088 \\
\hline & C.cuculata & 1.380 & 0.062 & 1.389 & 0.067 & 1.383 & 0.063 \\
\hline \multirow[t]{4}{*}{ Comp } & P. margaritifera & 0.769 & 0.025 & 0.772 & 0.021 & 0.765 & 0.026 \\
\hline & P. maculata & 0.761 & 0.029 & 0.767 & 0.026 & 0.767 & 0.029 \\
\hline & Chama sp. & 0.775 & 0.018 & 0.767 & 0.024 & 0.769 & 0.025 \\
\hline & C. cuculata & 0.777 & 0.019 & 0.773 & 0.018 & 0.768 & 0.028 \\
\hline \multirow[t]{4}{*}{ Ftype } & P. margaritifera & 0.992 & 0.007 & 0.994 & 0.004 & 0.991 & 0.006 \\
\hline & P. maculata & 0.984 & 0.011 & 0.990 & 0.009 & 0.991 & 0.004 \\
\hline & Chama sp. & 0.995 & 0.004 & 0.993 & 0.004 & 0.992 & 0.007 \\
\hline & C. cuculata & 0.996 & 0.004 & 0.995 & 0.006 & 0.994 & 0.002 \\
\hline \multirow[t]{4}{*}{ Ixy } & P. margaritifera & $4.471 E+05$ & $1.247 \mathrm{E}+07$ & $7.479 \mathrm{E}+05$ & $1.812 \mathrm{E}+07$ & $1.218 \mathrm{E}+06$ & $1.987 \mathrm{E}+07$ \\
\hline & P. maculata & $6.031 E+04$ & $2.503 E+06$ & $-3.451 \mathrm{E}+06$ & $2.023 E+06$ & $1.818 \mathrm{E}+05$ & $5.954+06$ \\
\hline & Chama sp. & $-1.668 E+06$ & $3.936 E+06$ & $-1.524 \mathrm{E}+07$ & $7.593 E+07$ & $3.555 E+04$ & $1.508 \mathrm{E}+07$ \\
\hline & C. cuculata & $1.998 \mathrm{E}+05$ & $5.548 \mathrm{E}+06$ & $-1.402 E+07$ & $5.360 \mathrm{E}+07$ & $8.762 E+06$ & $4.884 E+07$ \\
\hline
\end{tabular}

D: D larva; U: umbo larva; P: pediveliger. 
TABLE 3.

Comparison of 6 variable average values for each larval stage and each species at $5 \%$ level.

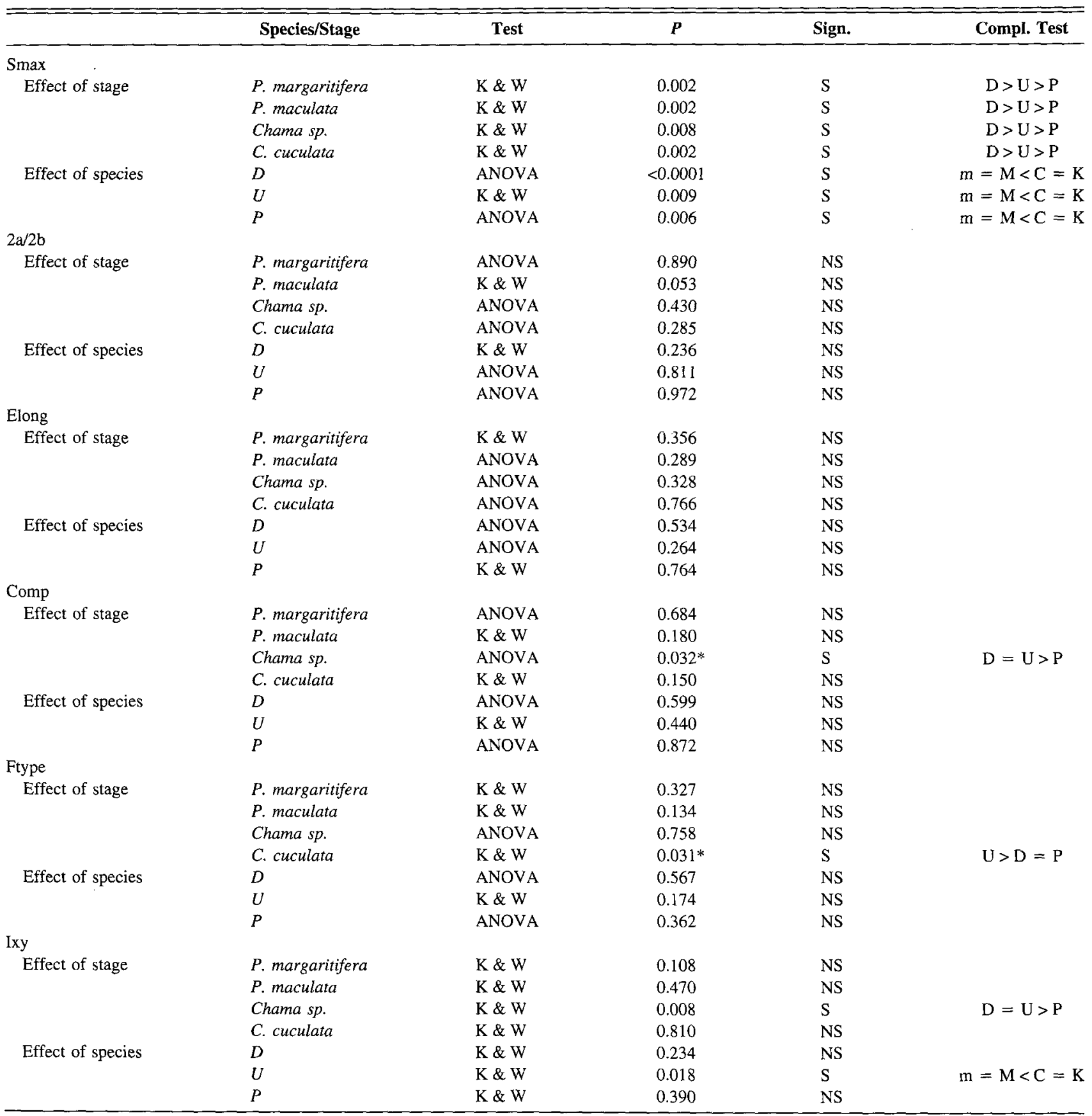

NS, Not significant; S, significant; D, D larva; U, umbo larva; P, pediveliger; M, P. mararitifera; $\mathrm{m}, P$. maculata; C, Chama; K, C. cuculata; K \& W: Kruskall \& Wallis. *: before Bonferroni correction.

a threshold to binarize the picture. The value 1 (corresponding to the larvae) was assigned to areas with gray value greater than the threshold, and the value 0 was assigned to areas with gray value lower than the threshold. Areas of value 1 that were not complete were filled in automatically and among them, only those corresponding to individualized larvae were retained and colored in red.

The Optilab software automatically numbers the retained red colored areas and describes them by performing a series of 42 measurements such as coordinates, optical density, dimensions and shape parameters. The best descriptors among this set of 42 were determined using principal component analysis (PCA). Six descriptors, the least dependent, were retained to establish a morphometric analysis pattern that would result in the specific identification of the 4 species of bivalves studied. They constituted the descriptive variables of larvae morphology (Fig. 1):

- the maximum intercept (Smax): length of the longest segment of the object, 
TABLE 4.

Correlation matrix of the 6 least correlated parameters selected after a PCA

\begin{tabular}{lcccccr}
\hline & Smax & 2a/2b & Elong & Comp & Ftype & Ixy \\
\hline Smax & 1 & & & & & \\
$2 \mathrm{a} / 2 \mathrm{~b}$ & 0.039 & 1 & & & & \\
Elong & 0.047 & 0.259 & 1 & & & \\
Comp & -0.127 & -0.113 & -0.524 & 1 & & \\
Ftype & -0.053 & -0.419 & -0.223 & 0.324 & 1 & \\
Ixy & -0.035 & -0.003 & -0.014 & -0.016 & 0.010 & 1 \\
\hline
\end{tabular}

None of these correlations are significant at the $5 \%$ level after Bonferroni correction.

- the Ellipse Ratio (2a/2b): ratio of the major axis to the minor axis of the equivalent ellipse,

- the Elongation Factor (Elong): ratio between Smax and the mean perpendicular intercept,

- the Compactness Factor (Comp): $A / A_{R}$ where $\mathrm{A}$ is the object area and $A_{R}$ is the area of the smallest rectangle containing the object,

- the moment of inertia (Ixy) representing the pixel distribution around the Center of Mass $x y$ : $\left(\sum x y\right)-A \cdot M x \cdot M y$, where $x y$ are the pixel coordinates, $M x$ is the Center of Mass $x[(\Sigma x) / A]$ and $M y$ is the Center of Mass $y[(\Sigma y) / A]$,

- the Type Factor (Ftype): $A^{2} / 4 \cdot \pi \sqrt{(I x x \cdot I y y)}$, where Ixx is the Inertia $\mathrm{xx}\left[\left(\Sigma x^{2}\right)-A \cdot M x^{2}\right]$ and Iyy is the Inertia yy $\left[\left(\Sigma x^{2}\right)-A \cdot M x^{2}\right]$.

\section{Data Analysis}

\section{Univariate Analysis}

The morphometric measurements of 4 species were classified into 3 subgroups corresponding to the main stages of physiological

$F 1$ and $F 2$ axes : $99 \%$

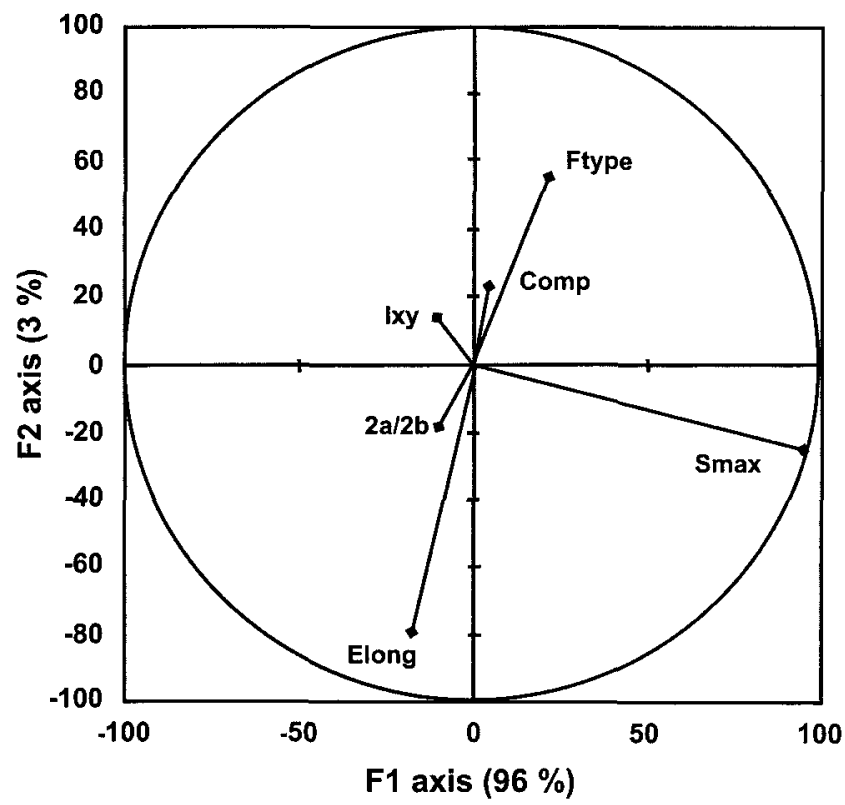

Figure 2. Correlation circle for $F 1$ and $F 2$ axes of the DFA applied to 6 measurements. Most of the interspecific variability $(96 \%)$ is represented by Smax on F1 axis.
Individuals (F1 and F2 axes: $99 \%$ )

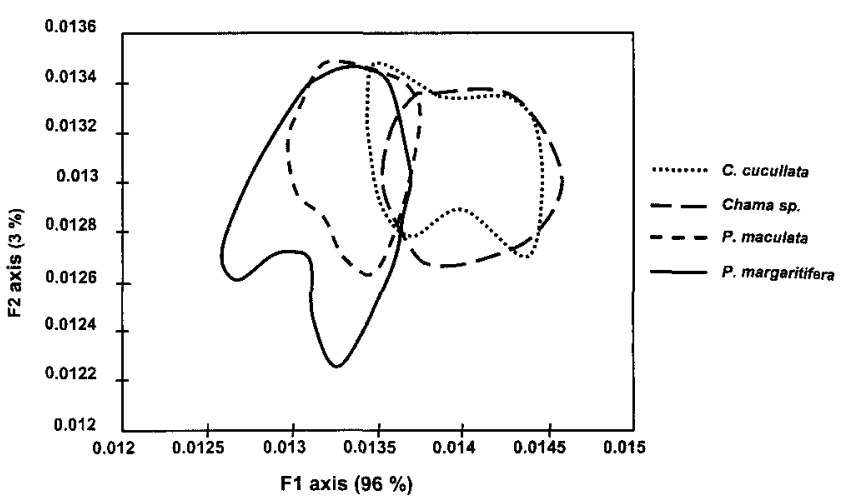

Figure 3. Situation of species patches in the F1-F2 canonical space. Patches are designed to contain approximately $95 \%$ of species dots. The best species discrimination, along F1 axis, separates the genus Pinctada on the left from Chama sp and Crassostrea cucullata on the right.

and morphological development: D larva (D), umbo larva (U) and pediveliger larva (P). An analysis of variance (ANOVA or test of Kruskall \& Wallis) was undertaken for each of the 6 descriptive variables according to the species and the larval stage.

\section{Discriminant Factor Analysis}

The discriminant factor analysis (DFA) was carried out with the help of Excelstat 5.1 software. The 6 descriptors retained to specifically discriminate the larvae were not significantly correlated (the highest $r$ was -0.524 between Elong and Comp). It was then possible to use a DFA approach to search for the combination of descriptors that maximized interspecific variability and minimized intraspecific variability (regardless of the larval stage encountered).

\section{Decision Tree}

This analysis, realized with Statistica 6 software, complemented DFA to identify larvae of the 4 species from the batches of hatchery monospecific larvae. Starting with all individuals attributed to the same species, it supplied a true-false determination model, with intermediate nodes of decision and terminal nodes of species attribution. The analysis stopped when the original species was found again with an error margin defined by the conditions for halting the segmentation, set here in advance to a minimum of 5 successive levels.

\section{Electron Microscopy}

About 10 hatchery larvae of each $P$. margaritifera and $P$. maculata species were prepared for SEM observation. Larvae were cleaned from organic matter in a bath of $10 \%$ chlorine water (Le Pennec 1978). This treatment was controlled under the microscope and was stopped by washing with distilled water as soon as degassing was observed within the valves. The prodissoconch valves were carefully separated using mounted pins and were dehydrated in a bath of $90^{\circ}$ alcohol. They were then set up on plots for metal plating. The valves thus prepared were observed under a HITACHI-S $3200 \mathrm{~N}$ scanning electron microscope. 
TABLE 5.

Specified identification success rate of individual larvae (all stage combined) by DFA.

\begin{tabular}{lcccc}
\hline \multicolumn{1}{c}{ True species } & C. cuculata & Chama sp. & P. maculata & P. margaritifera \\
\hline Individuals & 89 & 168 & 523 & 1,077 \\
Sorting & & & & 57 \\
C. cuculata & 23 & 117 & 33 & 0 \\
Chama sp. & 30 & 17 & 0 & 375 \\
P. maculata & 23 & 6 & 131 & $\mathbf{6 4 5}$ \\
P. margaritifera & 13 & $70 \%$ & $69 \%$ & $60 \%$ \\
Correct identification & $26 \%$ & &
\end{tabular}

\section{RESULTS}

\section{Univariate Analyses}

The mean values of the 6 descriptive variables of larvae morphology (Table 2) were compared by a one-way variance analysis or a Kruskall \& Wallis test (Table 3 ). Overall, there was no significant difference at the threshold of $5 \%$, between means of the different groups during the larval development, except for:

- Ftype of the $C$. cuculata $\mathrm{U}$ stage was significantly higher than that of the D and the P stages. This was not significant however after Bonferroni correction;

- Comp of Chama $s p$ was similar for the D to U larval phase but significantly smaller at the $P$ stage; this was not significant anymore after Bonferroni correction.

- Ixy of the Chama species at the P stage was significantly different from that of the $D$ or $U$ stages even after Bonferroni correction. It also allowed to differentiate this species from the other three for the stage $U$, but this was not significant after Bonferroni correction;

- Smax allowed distinguishing the three main stages of larval development regardless of the species, because all comparisons within species between stage were significant even after Bonferroni correction. All comparisons between species within stage were also significant even after Bonferroni correction and Smax was especially useful to significantly differentiate the group of individuals composed of $P$. margaritifera and of $P$. maculata from the group of individuals composed by Chama $s p$ and C. cuculata.

None of the six morphometric measurements allowed to discriminate alone the larvae of the four species. It was at best pos- sible to distinguish individuals of Chama $s p$ or of Crassostrea cuculata from those of $P$. margaritifera and of $P$. maculata.

\section{Discriminant Factor Analysis}

The principal component analysis (PCA) carried out on the 42 morphometric measurements allowed to retain among them the 6 least correlated parameters (Table 4).

The DFA results showed that the two first canonic axes F1 and F2 respectively represented $96 \%$ and $3 \%$ of the interspecific variability (Fig. 2). Smax corresponded mainly to F1 axis whereas Elong, in opposition to Ftype, corresponded more to F2 axis. The dot patches of the 4 species individuals are shown in the two dimensions canonical space set by axes F1 and F2 (Fig. 3). Groups of both Pinctada species individuals were clearly superimposed. Smax (mainly represented by F1 axis) allowed their discrimination, regardless of the larval stage, from the groups of Chama and Crassostrea cuculata species, superimposed as well. Further differentiation between the individuals of both species of Pinctada or between the Chama or $C$. cuculata species was not possible along F2 axis.

A Kullback statistical test revealed that the difference between the intragroup variance-covariance matrices was significant at $5 \%$ $\left(\mathrm{X}^{2}=2340.3 ; P<0,0001\right)$. The barycenters corresponding to the morphometry of the 4 studied species were significantly different (Wilks $\Lambda$ ratio $=0.433 ; F=99.88 ; P<0.0001$ ). A DFA was carried out based on these characteristic barycenters to try species identification of each larva previously measured, but the retained discriminant morphometric features were not sufficient. The identification success rates varied depending on the species (Table 5). They were comprised between $60 \%$ and $70 \%$ for both Pinctada species and the Chama genus, whereas only $26 \%$ was achieved for the Crassostrea genus.

TABLE 6.

Species identification success rate of D individual larvae by DFA.

\begin{tabular}{lcccc}
\hline \multicolumn{1}{c}{ True species } & C. cuculata & Chama sp. & P. maculata \\
\hline Individuals & 21 & 5 & 6 & \\
Sorting & & & 0 & 70 \\
$\quad$ C. cuculata & $\mathbf{1 5}$ & 0 & 0 & 0 \\
Chama $p p$. & 5 & 5 & 5 & 0 \\
$P$. maculata & 0 & 0 & 1 & 21 \\
$P$. margaritifera & 1 & $100 \%$ & $83 \%$ & 79 \\
Correct identification & $71 \%$ & 0 & $70 \%$ \\
\hline
\end{tabular}


TABLE 7.

Species identification success rate of U individual larvae by DFA.

\begin{tabular}{|c|c|c|c|c|}
\hline True species & C. cuculata & Chama sp. & P. maculata & P. margaritifera \\
\hline Individuals & 15 & 14 & 87 & 77 \\
\hline \multicolumn{5}{|l|}{ Sorting } \\
\hline C. cuculata & 10 & 3 & 2 & 1 \\
\hline Chama sp. & 4 & 8 & 1 & 0 \\
\hline P. maculata & 1 & 1 & 58 & 31 \\
\hline P. margaritifera & 0 & 2 & 26 & 45 \\
\hline Correct identification & $67 \%$ & $57 \%$ & $67 \%$ & $58 \%$ \\
\hline
\end{tabular}

Other DFA (Tables 6, 7 and 8) were undertaken on these samples to see if better species identification could be achieved at specific larval stages with the morphometric measures at hand. The correct identification rates were quite different from one species to another, but also between larval stages. The $\mathrm{D}$ and $\mathrm{P}$ stages gave the best species identification success rates overall.

\section{The Decision Tree}

A decision tree was built to help synthesize the results of the various DFA. Each morphometric measurement was assimilated to a prediction variable (specific identification criteria). After univariate preliminary studies, they were classified according to their potential $(0-100$ scale) to predict the dependent variable (species identity). Ftype, Smax, Elong and the larval stage had a potential of $100,96,72$ and 59 respectively to explain the dependent variable.

The organization of the tree was performed arbitrarily in the following manner: All of the larvae were allocated at first to the $P$. maculata species. If Smax was larger than $271 \mu \mathrm{m}$, the larva identity was changed for a Chama larva. If this condition was not true, the larva was still assigned to the $P$. maculata species until the next decision node. The overall process of the decision tree (Fig. 4) led to a discrimination key. Synthetic results of the larval identification using this discrimination key were better than those obtained with the former DFA (Table 9). However, species identification error rates were still generally higher than $25 \%$.

\section{Hinge Analysis by Electron Microscopy}

The hinge of the umbo larva of $P$. margaritifera is made up of a narrow provinculum bearing 4 denticles on the anterior edge and 6 on the posterior edge (Fig. $5-1$ ). The hinge of the umbo larva of $P$. maculata has a thick provinculum bearing 5 denticles on the anterior edge and 5 on the posterior edge (Fig. 5-2). There was no individual variation within species for these traits, thus hinge analysis of larval shells allowed the formal distinction between both species of the Pinctada genus within the larval phase.

\section{DISCUSSION}

Thirty-four species of bivalves were found in the lagoon of the atoll of Takapoto (Salvat \& Richard 1985). All of them are liable to produce larvae at the same time as the black lip pearl oyster. Therefore identification and monitoring of $P$. margaritifera larvae is not possible without means to discriminate this bivalve species from others present in the lagoon. The objective of this study was to test different morphological descriptors and to check whether the most pertinent among them could be used as tools for species determination.

The analysis of the shell profile using shape descriptors is a technique commonly used to determine numerous plankton species and was tested here. It was then related to the analysis of the hinge structure (ornamentation descriptors), a permanent criteria allowing a definite species determination (Le Pennec 1978).

Image analysis applied to morphometry has proven efficient in taxonomic identification (Garland \& Zimmer 2002). This method presents the advantage of replacing the observer by algorithms and thus minimizing the risk of subjective errors. It is fast and efficient for numerous applications, such as the study of zooplankton communities. (Beaulieu et al. 1999). The data generated are useful in solving taxonomy questions and sometimes even to identify morphological variation among populations within a species (Jeffries et al. 1984, Ishii et al. 1987, Cadrin \& Friedland 1999). Whereas morphometric analysis is successful at species identification in some cases, it is more difficult for a number of others. This is the case of a few copepods and fish larvae as described by Naudin et

TABLE 8.

Species identification success rate of $\mathbf{P}$ individual larvae by DFA.

\begin{tabular}{|c|c|c|c|c|}
\hline True species & C. cuculata & Chamasp. & P. maculata & P. margaritifera \\
\hline Individuals & 46 & 152 & 423 & 316 \\
\hline \multicolumn{5}{|l|}{ Sorting } \\
\hline C. cuculata & 21 & 38 & 1 & 2 \\
\hline Chama sp. & 19 & 91 & 0 & 0 \\
\hline P. maculata & 4 & 16 & 312 & 108 \\
\hline P. margaritifera & 2 & 7 & 110 & 206 \\
\hline Correct identification & $46 \%$ & $60 \%$ & $74 \%$ & $65 \%$ \\
\hline
\end{tabular}




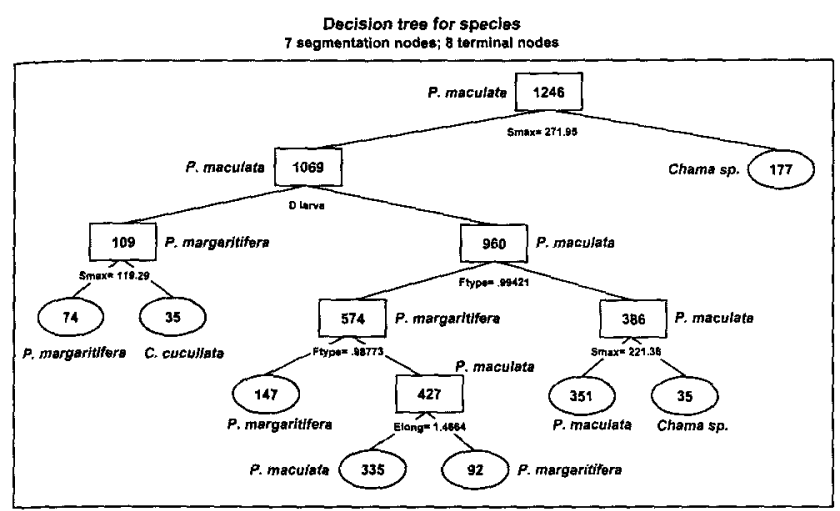

Figure 4. Decision tree for discrimination of the four species. Each rectangle box represents a segmentation node under which value of the discrimination factor is given. Each ellipse box represents a terminal node of species determination. Numbers given in the node boxes represent larvae counts.

al. (1996). The transparency of the objects to analyze is a widely encountered difficulty. In the case of bivalve larvae, the shells are translucent but their profiles are generally sufficiently contrasted from the rest of the picture and correspond to closed forms. It is then possible to use data processing tools to analyze each picture, cut out all closed forms and describe them according to contour, area and position in the picture.

The measurements performed on all of the larval stages of the 4 bivalve species studied here provided information on some of their distinctive dimensions according to age.

Univariate analyses showed that Smax was the most discriminating measure between stage within species and between species within stage. The multivariate analyses gave better results. Some degree of species identification among the larvae of the 4 species was possible, but the rates of success were different according to the methods used:

- Using DFA, the larvae discrimination of $P$. margaritifera, of $P$. maculata, of Chama and of $C$. cuculata was achieved with probabilities of success of $60 \%, 69 \%, 70 \%$ and of $26 \%$ respectively.

- With the decision tree approach, the larvae discrimination of $P$. margaritifera, of $P$. maculata, of Chama and of $C$. cuculata was achieved with probabilities of success of $74 \%, 63 \%, 69 \%$ and of $77 \%$ respectively.

Despite these positive results, the descriptors studied here cannot be considered adequate for the identification of Pinctada and
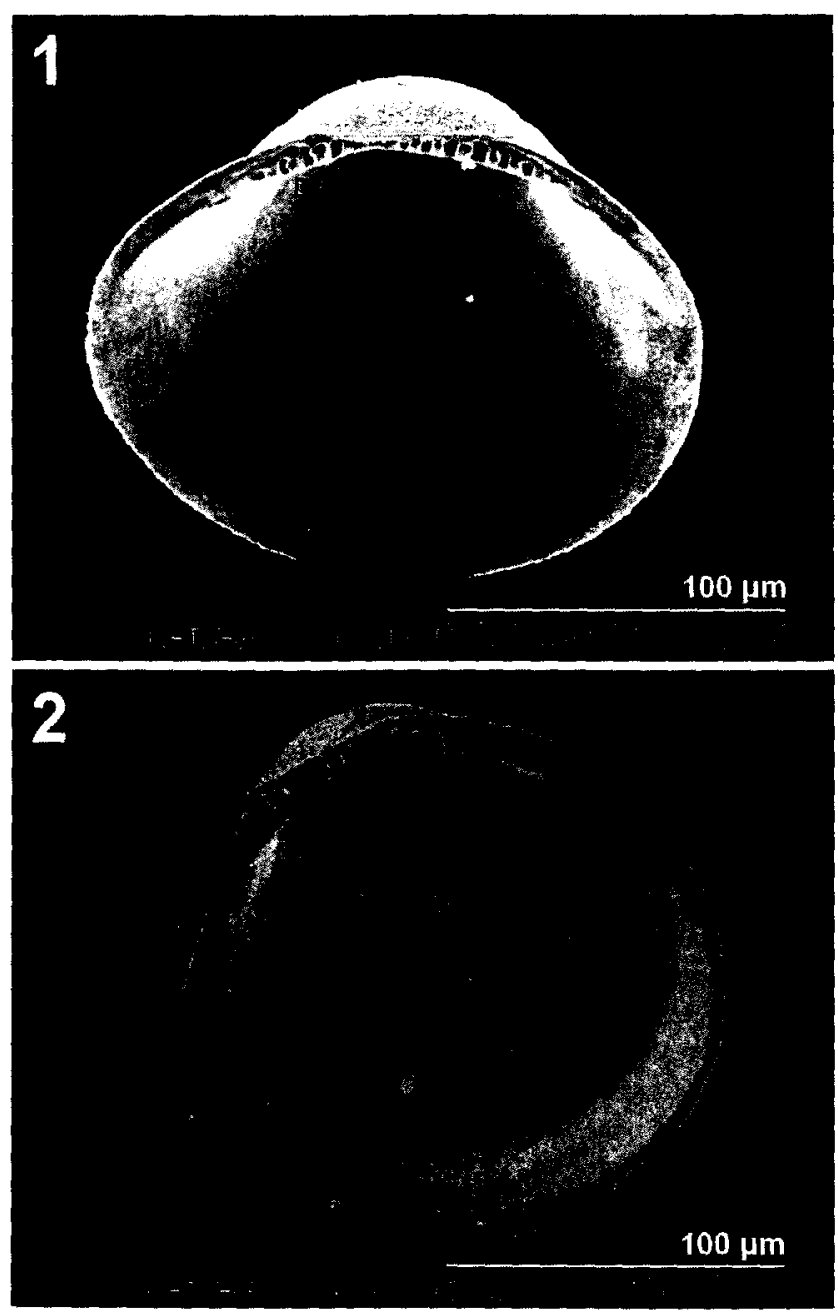

Figure 5. SEM photographs of right valve of $P$. margaritifera (1) and $P$. maculata (2) larvae. Numbers of anterior teeth $(\mathrm{Da})$ and of posterior teeth (Dp) of the hinge are invariant and differ between both species.

other bivalve larvae in plankton samples. A higher reliability and a success probability close to $90 \%$ would be required, as suggested in the literature (Jeffries et al. 1984, Naudin et al. 1996, Rahhou, 2003). Similar discrimination rates (up to $74 \%$ ) between bivalve larvae were obtained by Hendriks et al. (2005), who concluded that shape characteristics combined with computer analysis did not provide tools conclusively useful for young bivalve larvae identification.

TABLE 9.

Species identification success rate of $P$ individual larvae using a decision tree.

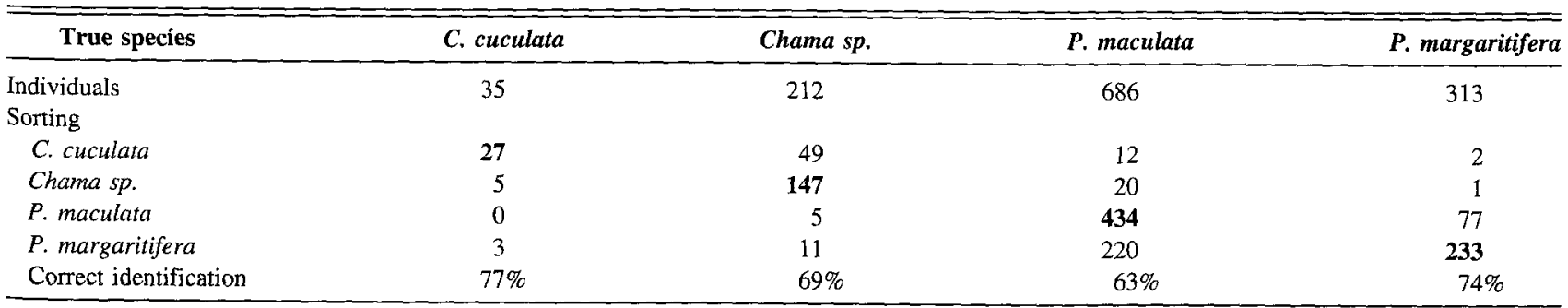


Another problem is that the acquired image of the larva form can vary between records, according to the orientation of the shell. To avoid image distortion and measurement errors, the separation plane between valves should be parallel to the sensor plane. Accuracy may also improve with additional measurement of the valve thickness. This descriptor has already been the subject of an original application as a quality indicator of larval development for Pecten maximus (Salaün et al. 1991). Image multiacquisition resulting from slightly moving the observed larva or changing the angle of light reaching the larva may also help in selecting larval areas that present the largest Smax.

More sophisticated mathematical contour descriptors such as Fourier descriptors (Crampton 1995) could also be considered, because it is possible to decompose the contour of an object using the Fourier elliptic transform. This method has already been proposed by Gevirtz (1976) to evaluate specific and intraspecific variability amongst bivalves, and these descriptors have been successfully used to distinguish similar mussel species (Crampton 1995, Innes \& Bates 1999) and to identify eel populations based on otholith shape (Rahhou 2003). Davis et al. (1996) anticipate ongoing improvement of these visualization techniques for plankton identification, but phenotypic plasticity during larval development will limit their accuracy (Garland \& Zimmer 2002).

The method of valve hinge analysis proved again its discrimination potential (Le Pennec 1978) in the present study. It enabled a definite distinction of both Pinctada species according to the number of denticles and to the thickness of the provinculum. However, the preparation time for each larva and the necessary handling precautions remain incompatible with the goal of a fast characterization of large-scale distributions and abundances of larvae.

Considerable progress has been achieved with other techniques of larval identification, which are not based on the morphological but on the molecular characteristics of each species. Two tracks are being explored at this time for species identification and discrimination of bivalve larvae. One relies on genetics tools (LopezPiñon et al. 2002, Wood et al. 2003, Hosoi et al. 2004) and the other on immunological approach (Paugam et al. 2000, Abalde et al. 2003).

The DNA markers present the advantage of being independent of age or physiological condition of the individuals. It is therefore possible to use individual adults to develop probes that are efficient on larvae. However, their use requires in most cases that the plankton sample be destroyed, and therefore they are better suited as overall indicators of presence and representation within a sample, rather than as real probes for individual marking.

The advantage of the immunological identification over genetic identification is that the antibodies find in the plankton sample the larvae against which they have been induced and specifically mark them without altering the shell structures (Paugam et al. 2003). However the induction of an efficient antibody production requires the availability of large amounts of larvae of different species that can only be obtained in the hatchery.

The analysis of the hinge characteristics is the only method available today which would ensure identification of the $P$. mar. garitifera pearl oyster larvae. However, this method is too cumbersome to authorize a rapid identification of the larvae and cannot be used in real time for long term systematic plankton sampling. It could, however, be used to validate any other technique of larva, species identification. Any improvement of these techniques will be useful for following larvae within the plankton and to develop our knowledge of the larval life cycle of the $P$. margaritifera pearl oyster in the lagoons of French Polynesia.

\section{LITERATURE CITED}

Abalde, S. L., J. Fuentes \& A. Gonzalez-Fernandez. 2003. Identification of Mytilus galloprovincialis larvae from the Galician rias by mouse monoclonal antibodies. Aquaculture 219:545-559.

Beaulieu, S. E., M. M. Mullin, V. T. Tang, S. M. Pyne \& B. S. Twining. 1999. Using an optical plankton counter to determine the size distributions of preserved zooplankton samples. J. Plankt. Res. 21:19391956.

Cabral, P., K. Mizuno \& A. Tauru. 1985. Preliminary data on the spat collection of mother of pearl (Pinctada margaritifera, Bivalve, Mollusc) in French Polynesia. In: B. Delesalle, R. Galzin \& B. Salvat, editors. Proceedings of the 5th International Coral Reef Congress, Tahiti, French Polynesia. 5. pp. 177-182.

Cadrin, S. X. \& K. D. Friedland. 1999. The utility of image processing techniques for morphometric analysis and stock identification. Fish. Res. 43:129-139.

Crampton, J. S. 1995. Elliptic Fourier shape analysis of fossil bivalves: some practical considerations. Lethaia 28:179-186.

Davis, C. S., S. M. Gallager, M. Marra \& W. K. Stewart. 1996. Rapid visualization of plankton abundance and taxonomic composition using the video plankton recorder. Deep-Sea Res. 43:1947-1970.

Garland, E. D. \& C. A. Zimmer. 2002. Techniques for the identification of bivalve larvae. Mar. Ecol. Prog. Ser. 225:299-310.

Gevirtz, J. L. 1976. Fourier analysis of bivalve outlines: Implications on evolution and autecology. Math. Geol. 8:151-163.

Hendriks, I. E., L. A. van Duren \& P. M. J. Herman. 2005. Image analysis techniques: A tool for the identification of bivalve larvae? J. Sea Res. 54:151-162.
Hosoi, M., S. Hosoi-Tanabe, H. Sawada, M. Ueno, H. Toyohara \& I. Hayashi. 2004. Sequence and polymerase chain reaction-restriction fragment length polymorphism analysis of the large subunit rRNA gene of bivalve: Simple and widely applicable technique for multiple species identification of bivalve larva. Fish. Sci. 70:629-637.

Innes, D. J. \& J. A. Bates. 1999. Morphological variation of Mytilus edulis and Mytilus trossulus in eastern Newfoundland. Mar. Biol. 133:691699.

Ishii, T., R. Adachi, M. Omori, U. Shimizu \& H. Irie. 1987. The identification, counting, and measurement of phytoplankton by an image processing system. J. Cons. Int. Explor. Mer. 43:253-260.

Jeffries, H. P., M. S. Berman, A. D. Poularikas, C. Katsinis, I. Melas, K. Sherman \& L. Bivins. 1984. Automated sizing, counting and identification of zooplankton by pattern recognition. Mar. Biol. 78:329-334.

Le Pennec, M. 1978. Genèse de la coquille larvaire et post-larvaire chez divers Bivalves marins. Thèse de doctorat d'Etat, Faculté des Sciences, Brest, France. 229 pp, 108 pl.

Lopez-Piñon, M. J., A. Insua \& J. Mendez. 2002. Identification of four scallop species using PCR and restriction analysis of the ribosomal DNA internal transcribed spacer region. Mar. Biotechnol. 4:495-502.

Naudin, S., H. Pella, N. Charlon, J. Garric \& P. Bergot. 1996. Détection des larves de poisson anormales par analyse d'image. Aquat. Living Ressour. 9:281-287.

Paugam, A., M. Le Pennec \& G. André-Fontaine. 2000. Immunological recognition of marine bivalve larvae from plankton. J. Shellfish Res. 13:547-553. 
Paugam, A., M. Le Pennec, A. Marhic \& G. André-Fontaine. 2003. Immunological in situ determination of Pecten maximus larvae and their temporal distribution. J. Mar. Biol. Ass. U.K. 83:1083-1093.

Rahhou, I. 2003. Contribution à la connaissance de la population d'anguille (Anguilla anguilla L. 1758) dans le système Moulaya/Méditérranée: Ecologie et parasitologie. Thèse de doctorat. Université Mohamed ler, Faculté des Sciences d'Oujda. $153 \mathrm{pp}$.

Salaün, M., J. Boucher \& M. Le Pennec. 1991. Prodissoconch shell char- acteristics as indicators of larval growth and viability in Pecten maximus (Linnaeus, 1758). J. Shellfish Res. 1:37-46.

Salvat, B. \& G. Richard. 1985. Atoll de Takapoto, archipel des Tuamotu. In: B. Delesalle, R. Galzin \& B. Salvat, editors. Proceedings of the 5 th International Coral Reef Congress, Tahiti, French Polynesia. 1 pp. 325-377.

Wood, A. R., A. R. Beaumont, D. O. F. Skibinski \& G. Turner. 2003. Analysis of a nuclear-DNA marker for species identification of adults and larvae in the Mytilus edulis complex. J. Molluscan Stud. 69:61-66. 